\title{
Crime and Youth Unemployment in the Cato Manor Policing Area of Kwazulu-Natal, South Africa
}

\author{
Trevor B. Small \\ Emeka E. Obioha \\ Department of Safety and Security Management, Tshwane University of Technology, Pretoria 0001, South Africa \\ Email: obiohaee@tut.ac.za, emekaobioha@gmail.com
}

\section{Doi:10.5901/mjss.2014.v5n23p2318}

\section{Abstract}

\begin{abstract}
Crime statistics in the Cato Manor policing area has, for the past five years (2005 to 2010), shown a constant increase in property related crime perpetrated by youth. There are many youth on the streets of Cato Manor who idle, loitering on street corners, at game shops, at shopping centres or just sit outside their residences. The objective of this study was to investigate crime and criminal behaviour patterns in the area, the social and economic conditions associated with criminal activity in order to identify the most important and prevailing factors and to assess the role of unemployment on criminal activity among youth. For the purpose of the study, participatory action research was used for the qualitative research which assisted in gaining an understanding into the life of the participant. In-depth interviews were conducted with the use of standardized in-depth interview guides. Surveys, utilizing structured questionnaires were used to obtain the quantitative data. The study found that most respondents were unemployed at the time of first arrest. However, the contributing conditions and factors to crime are not limited to unemployment. More compounding factors such as dysfunction in the family, plays a role in the trends observed. The majority of respondents were raised by single parents, respondents formed friendships with youth of similar backgrounds and 65 percent of respondents committed crime with one or more friends. The criminal lifestyle was rewarding up until time of arrest. The study concluded that there is a relationship between unemployment and crime in the Cato Manor policing area. Contributing factors of crime are not limited to unemployment. Opportunities given to offenders regarding rehabilitation are mostly taken, however, some youths' lives are so adversely affected that they see no other life than that of crime.
\end{abstract}

Keyword: Policing, Crime, Unemployment, Youth, South Africa

\section{Introduction}

The adoption of the National Crime Prevention Strategy (NCPS) by the South African government in 1996 signaled a new approach to fighting crime in South Africa. The fresh tactics were concerned with a coordinated effort to deal with the effects and root causes of crime. The new approach attempted to involve civil society partners as well as governmental agencies, such as the police, courts and correctional services, which are considered by many to be responsible for eradicating crime (National Crime Prevention Strategy, 1996:5-6). Inspite of these efforts and approaches, crime rates and victimizations are increasing on daily basis in most locations and communities in South Africa.

Crime statistics in the Cato Manor policing area of Durban, South Africa for the period 1 April 2005 to 31 March 2010, (Table 1) clearly show the extent of the unacceptably high crime situation in the relatively small geographic area. Unarguably, if the fight against crime is to have any meaning, it is essential to thoroughly understand the crime situation in each specific context. Crime is a complex phenomenon with a number of factors interacting at any given time. These factors are sometimes referred to as risk factors and include the so-called "root causes" of crime. In this context (cause and manifestation) it can justifiably be argued that the risk factors which produce crime, and not the perpetrators of crime, should be the primary focus of crime combating efforts. Radical as it may sound, it can be argued that it is not so much the success of the police against criminal offenders, but much rather the success achieved with the elimination of risk factors, which will determine the levels of crime (Burger, 2007:45). Examining the social causes of crime in South Africa, Chris De Kock, the head of the police's Crime Information Analysis Centre, commenting on the release of the S.A. Police's annual report and crime statistics for $2005 / 2006$, states that the only way to prevent social crime is through socioeconomic development and by changing the living conditions of people in this country. Urbanization, unemployment, poverty, growing material needs and substance abuse were among the factors cited by De Kock as contributing to socially determined crimes (SAPS Annual Report, 2006). At present, unemployment in South Africa has increased since 
1995. The official unemployment rate was $20 \%$ in 1994, falling to $16,9 \%$ in 1995 and rising to $21 \%$ in 1996 and to $22,9 \%$ in 1997. In 1997 official unemployment rates were highest for African people (29\%), followed by Colored (16\%), Indian $(10 \%)$ and then white (4\%). Using the official definition, $10 \%$ of the economically active in the oldest age group (46-65yrs) and $19 \%$ of those in the middle group (31-45yrs) were employed compared to $35 \%$ of those in the youngest age group (15-30yrs) (Statistics S.A., 2001).

Table 1: Crime Statistics for Cato Manor for the period 1 April 2005 to 31 March 2010

\begin{tabular}{|lccccc|}
\hline & $\mathbf{2 0 0 5}$ & $\mathbf{2 0 0 6}$ & $\mathbf{2 0 0 7}$ & $\mathbf{2 0 0 8}$ & $\mathbf{2 0 0 9}$ \\
\hline Common Robbery & 106 & 97 & 106 & 176 & 78 \\
Armed Robbery & 143 & 110 & 135 & 145 & 81 \\
Housebreaking Residential & 253 & 267 & 247 & 338 & 293 \\
Theft of motor vehicle & 36 & 62 & 37 & 54 & 52 \\
Carjacking & 37 & 33 & 66 & 39 & 53 \\
Theft General & 204 & 281 & 297 & 219 & 251 \\
Housebreaking Business & 14 & 14 & 30 & 14 & 34 \\
Robbery with weapon & 66 & 54 & 47 & 56 & 41 \\
Theft out of motor vehicle & 60 & 102 & 66 & 64 & 42 \\
\hline
\end{tabular}

Source: Crime Intelligence Analysis Centre of the station

However, it is also acknowledged that reaching a conclusion that the escalating crime rate is caused by a high rate of unemployment, is dangerous and unhelpful. The research by Cambridge economist Daniel Dickinson and the Probation Service making this link should be treated with the greatest caution. In an article published in "Psychological Reports in 1993" David Lester concluded, from his research, that from 1960 to 1988 the unemployment rate was negatively associated with crime rates in the U.S.A. No reasonable person would totally deny that unemployment may well erode those social restraints where they do exist, but it is unwise to make a generalization that unemployment causes crime (Coad, 2007). The intention of this study is also to ascertain whether there is any pressure being placed on these youth by their peers by other social forces. The findings will dictate whether there will be grounds to embark on a form of social crime prevention strategy, in order to address the root causes of the crimes of armed robbery, robbery, theft and burglary in the study area.

The main objective of this study is to understand the inter-relationship between crime and the unemployment situation in the Cato Manor Policing Area, and specifically to to investigate the social and economical conditions associated with criminal activity, in order to identify the most important and prevailing factors; and assess the role of the unemployment rate on criminal activity among the youth.

Based on the objectives of this study three research assumptions were set to deepen the understanding of the dimensions of the problem in the area of study, viz

Assumption 1: Unemployed Youth Residing in Cato Manor Commit Crime to Sustain Themselves

Assumption 2: Youth who are Unemployed for Lengthy Periods turn to Crime.

Assumption 3: Property Related Crime in Cato Manor is a Direct Result of Unemployment

\section{Research Design and Methodology}

The study was conducted in the policing area of Cato Manor. The policing area of Cato Manor covers an area of 25 square kilometers with upper class, middle class and lower class citizens, an industrial area and informal settlements. For the purpose of the qualitative study and to obtain the most accurate result, the most suitable environment is the prison where youth (over 21 years) are incarcerated and youth who have been sentenced to places of safety, such as Excelsior Place of Safety in Pinetown and Durban, in order to trace those who have been through the criminal justice system. The Department of Correctional Services, Community Corrections, was used to trace youth who were sentenced to do community service, as a result of the property related crimes they had committed.

The researcher was assisted by the department of Corrections in finding youth in the universe that fit the profile of residing in the Cato Manor area, who have been convicted for property related offences and who are currently serving sentences in Westville Prison, as well as those who are serving sentences of community service within the communities in which they reside. Two hundred youth were found out of which ninety five were involved in the survey, while nineteen 
were interviewed for the qualitative study.

When adopting a qualitative approach to the study, a Participatory Action Research Approach was used. In order to obtain a true reflection of the potential youth offenders in the community, a quantitative approach in the form of surveys, was conducted. This took the form of structured questionnaires with control groups. A qualitative study was conducted amongst convicted youth, in the last five years. The general aim of this study was to gather information from youth who reside in the Cato Manor area, who have been convicted of criminal offences, generally, or specifically property crime and contact crime involving the appropriation of property.

The data analysis process was conducted by making use of the available computer aided software, such as Nud*ist, Winmax and Hyperqual, for the analysis of qualitative data, as well as various spreadsheet formats for quantitative data, which was used as a "tool" to aid in the management of data for the storage and retrieval of information. For this purpose, Statistical Package for the Social Sciences (SPSS) was used for the analysis of the quantitative data generated through a quantitative approach.

\section{Research Findings}

\subsection{Social and Economic Conditions associated with Criminal Activities in Cato Manor}

The study reveals that less than $30 \%$ of respondents grew up with both parents. Table 2 indicates that two thirds of those who did not grow up with both parents grew up with a single parent, $20 \%$ with grandparents and the remainder with a guardian. In more than $60 \%$ of the cases the respondent's mother is not the father's only wife. The study further indicates that $51.6 \%$ of respondents have close friends while $48.4 \%$ did not have any close friends. Just over half the respondents have a close group of friends. Of those that said that they have a group of close friends, $63 \%$ have one friend and $37 \%$ have two or more friends. Only one third of respondents are satisfied with what they own. Two thirds sometimes want possessions and clothing that belong to their friends. Of those friends who had been arrested for property related offences, $60 \%$ had been arrested once and the remaining $40 \%$ more than once. It is also shown further in the study that the respondent, in two thirds of instances, were with one or more friends when the crime was committed, however in most cases (47.4\%) it was with one friend, while $33.7 \%$ were alone when they committed crime.

Table 2: Social and economic conditions associated with criminal activities

\begin{tabular}{|lccc|}
\hline & YES & NO & TOTAL \\
\hline Grew up with parents & $29.0 \%$ & $71.0 \%$ & $100 \%$ \\
Mother is father's only wife & $38.4 \%$ & $61.6 \%$ & $100 \%$ \\
Have close friends & $51.6 \%$ & $48.4 \%$ & $100 \%$ \\
Friends have been arrested for property related crime & $60.0 \%$ & $40.0 \%$ & $100 \%$ \\
\hline
\end{tabular}

As shown in Table 3, respondents who were part of a family of more than three siblings made up $63.8 \%$ of the respondents in the study, while $36.2 \%$ of respondents were part of a family with less than three siblings. The group where the respondent was the only sibling, contributed to $5.3 \%$ of the study. Respondents in a family of more than three siblings had to assist in providing for the needs of the family, as the need was greater in larger families. In terms of whether the respondents' parents have been to prison, the study reveals that $70 \%$ of the respondents' fathers had been to prison, whilst only $30 \%$ of respondents' mothers had been to prison. Sixty seven and a half percent of respondents were unemployed at the time of their arrest, whilst $32.5 \%$ were employed. Considering the number of persons the respondent was with when the crime was committed, the study clearly indicates that $47.4 \%$ of the respondents were with one friend, $33.7 \%$ were alone and $18.9 \%$ of respondents were with more than one friend when the crime was committed. This finding supports the theory that the unemployment status of respondents attributed to their commission of crime, purely because of their need to provide for themselves and their family and these crimes were committed in the company of a friend with a similar background. 
Table 3: Social and economic conditions associated with criminal activities

\begin{tabular}{|llcc|}
\hline & & Frequency & Percentage \\
\hline \multirow{3}{*}{ Number of children in family } & Less than three & 34 & $36.2 \%$ \\
& More than three & 60 & $63.8 \%$ \\
& Total & 94 & $100 \%$ \\
Parents been to prison & Father & 10 & $70.0 \%$ \\
& Mother & 3 & $30.0 \%$ \\
& Total & 13 & $100 \%$ \\
Employment status at time of arrest & Employed & 26 & $32.5 \%$ \\
& Unemployed & 54 & $67.5 \%$ \\
& Total & 80 & $100 \%$ \\
& Alone & 32 & 33.7 \\
& With one friend & 45 & 47.4 \\
& With more than one friend & 18 & 18.9 \\
& Total & 95 & $100 \%$ \\
\hline
\end{tabular}

The study (Table 4) revealed that, when looking at the age of the respondent in relation to the number of friends the respondent was with at the time of committing crime, in the age category 18-21years $54.1 \%$ were alone, $35.1 \%$ were with one friend and $10.8 \%$ were with more than one friend. In the age category $21-24 y e a r s 66.7 \%$ percent were with one friend, while $22.2 \%$ were with more than one friend. In the age category above $25 y e a r s ~ 45.2 \%$ were with one friend, while $29 \%$ were alone. The finding of younger offenders committing crime alone indicates that certain property crimes, which were opportunistic, were committed alone, whereas the more difficult crimes needed accomplices to succeed. It also indicates that the older the respondents grew, the more the type of crime escalated into more serious crime.

Table 4: Relationships between age of respondents and number of accomplices

\begin{tabular}{|cccccc|}
\hline & \multicolumn{4}{c|}{ Accomplice } & \multirow{2}{*}{ Total } \\
\cline { 3 - 5 } & & Alone & With one friend & With more than one friend & \\
\cline { 3 - 5 } Age & $54.1 \%$ & $35.1 \%$ & $10.8 \%$ & $100 \%$ \\
& $18-21$ & $11.1 \%$ & $66.7 \%$ & $22.2 \%$ & $100 \%$ \\
& $21-24$ & 29.05 & $45.2 \%$ & $25.8 \%$ & $100 \%$ \\
\cline { 3 - 5 } & $>25$ & $33.7 \%$ & $47.4 \%$ & $18.9 \%$ & $100 \%$ \\
\hline
\end{tabular}

When looking at school qualification in relation to close friends, the study (Table 5) showed that there was a marginal difference between respondents with high school qualification or higher (51.1\%), as opposed to respondents with primary school qualification (48.9\%). The study further revealed that $62.5 \%$ of close friends have been arrested before, as opposed to $57.8 \%$ of close friends who had not been arrested before.

In the study, respondents were questioned as to their affiliation with close friends and the study revealed that $42.9 \%$ of respondents with a primary school or lower education had a group of close friends and $59.1 \%$ said that they did not have close friends. Further, about $56 \%$ of respondents with a high school qualification or higher had a close group of friends, while $43.6 \%$ did not have a close group of friends.

Table 5: Relationship between High School qualification of respondents and group of close friends

\begin{tabular}{|llccc|}
\hline & & \multicolumn{2}{c|}{ Close friends } & Total \\
\cline { 3 - 3 } & & Yes & No & \\
\cline { 3 - 3 } School & Primary school or lower & $42.9 \%$ & $57.1 \%$ & \\
Total & High school or higher & $56.4 \%$ & $43.6 \%$ & $100 \%$ \\
\hline
\end{tabular}

Respondents revealed (Table 6) that $57.8 \%$ of them had close friends and of these close friends, $62.5 \%$ had been arrested before. 
Table 6: Relationships between friends of respondents arrested and group of close friends

\begin{tabular}{|lccc|}
\hline & Yes & No & Total \\
\hline Friends arrested & $62.5 \%$ & $37.5 \%$ & $100 \%$ \\
Group of close friends & $57.8 \%$ & $42.2 \%$ & $100 \%$ \\
Total & $60.2 \%$ & $39.8 \%$ & $100 \%$ \\
\hline
\end{tabular}

\subsection{Influence of Unemployment Status on Criminal Activity}

The employment status of respondents in relation to employment, as shown in Table 7, revealed that $64.9 \%$ of respondents in all age categories were employed, while $35.1 \%$ had not been employed. The table further revealed the type of crimes committed and whether the respondents were employed or not. It showed that $64.5 \%$ of respondents were employed when they committed crime, while $35.5 \%$ were unemployed.

Table 7: The relationship between the employment status of respondents and the type of offence committed

\begin{tabular}{|c|c|c|c|c|c|c|c|c|}
\hline \multirow{4}{*}{ Employed } & & \multicolumn{6}{|c|}{ Type of crime committed } & \multirow{2}{*}{ Total } \\
\hline & & House-breaking & Robbery & Theft & Theft of $\mathrm{m} / \mathrm{v}$ & Murder & Other & \\
\hline & Yes & $62.5 \%$ & $73.3 \%$ & $50.0 \%$ & $100 \%$ & $50.0 \%$ & $100 \%$ & $64.5 \%$ \\
\hline & NO & $37.5 \%$ & $26.7 \%$ & $50.0 \%$ & $0 \%$ & $50.0 \%$ & $0 \%$ & $35.5 \%$ \\
\hline Tota & & $100 \%$ & $100 \%$ & $100 \%$ & $100 \%$ & $100 \%$ & $100 \%$ & $100 \%$ \\
\hline
\end{tabular}

However in Table 8, when looking at the employment status at the time of arrest and the number of times arrested, the study revealed that $70 \%$ of respondents that were unemployed were arrested once or more than once. This finding indicates that, although these respondents were employed at the time of arrest, the income received was not enough to sustain them and also that turning to crime became more lucrative than their mediocre employment. The study also reveals that the predominant crime committed by those respondents who were employed was that of housebreaking, as well as robbery and those who were unemployed committed more housebreakings.

The study also revealed, when looking at the relationship between the employment status of respondents at the time of arrest and the number of times they were arrested, that among those who were employed at the time of arrest, $29.45 \%$ were arrested once, while $30.8 \%$ were arrested more than once. Of those respondents who were not employed at the time of arrest $70.6 \%$ were arrested once, while $69.2 \%$ were arrested more than once. This finding indicates to the researcher that the respondents found that crime was paying off; that committing crime was the only way of obtaining money and that being arrested was only a consequence which did not deter the respondents. After being arrested, employment opportunities became bleaker and respondents went back to committing crime and this way of life became more of a reality to the respondents. Respondents indicated that drugs, bad friends and unemployment were the main prompts for committing crime in Cato Manor.

Table 8: Relationship between the employment status of respondents at time of arrest and the number of times arrested

\begin{tabular}{|ccccc|}
\hline & & \multicolumn{2}{c|}{ Number of times arrested } & \multirow{2}{*}{ Total } \\
\cline { 3 - 3 } & & Once & More than once & \\
\cline { 3 - 3 } Employment status & Employed & $29.4 \%$ & $30.8 \%$ & $29.9 \%$ \\
& Unemployed & $70.6 \%$ & $69.2 \%$ & $70.1 \%$ \\
Total & & $100.0 \%$ & $100.0 \%$ & $100.0 \%$ \\
\hline
\end{tabular}

\subsection{Interrogating the Contributory Situational Drivers of Crime and criminalities in Cato Manor}

Social (family) backgrounds play a very important role in the development of an individual into adulthood, as pointed out by previous studies (Lab, 2010:178) on the topic that the lack of proper upbringing may lead to a whole range of adverse activities been perpetrated by youth. In this study we observe that most of the respondents grew up without both parents. In most cases a single mother brought them up. A case where a single father has raised a respondent, in this sample, is extremely rare. In the families of many of the respondents the father was absent. This can be deduced or further substantiated from the following: in most families with a single parent children were brought up by the mother; except for 
questions linked to other questions, the questions in the questionnaire with the highest non-response rate are those concerning information on the father of the respondent. The main reason why these questions were not answered is that the respondent does not know his/her father; most of the respondents could not supply information on their father's education and employment. The reasons given were that they do not know their fathers or that he had passed away; in most of the cases the mother is not the father's only wife. The fathers therefore divide their time and money between two or more step-nuclear families; a small percentage of fathers have been to prison. Most of the respondents are from families with three or more children. Furthermore one or both parents are unemployed. For many of the families, the breadwinner is the mother, doing a low paid job such as cleaning, sewing or domestic work. This means that the respondents grow up in poor families. Families with more than three children appear to be a contributing factor to crimes committed by people without a tertiary education.

Peer groups have an influence, be it positive or negative, on the life of youth, as studies have shown that youth carry out what they have been taught at home in their friendship environment, to determine whether thoughts on life are similar amongst friends and that determines whether the influence on their lives is positive or negative. If youth have a good foundation in their upbringing through their family, school and religious environment it could lead to positive influences amongst friends. In the present study, most of the respondents have a close group of friends. According to the study, the wrong friends can influence people to use drugs and commit crimes. Most of the respondents indicated that they sometimes want possessions and clothing that friends have. They also reported that their friends have history of arrest and of those arrested most were arrested more than once. Association with the wrong friends appears to be a contributing factor for crimes committed by youth with tertiary education qualifications.

Education leads to employment success, albeit only high school education, as youth could develop themselves further from there. In this study most respondents regard education as important. Only a small number of the respondents completed high school. Most of the respondents that were interviewed did obtain a trade while in prison. Respondents' education levels are about the same as that of their fathers. Upon looking further at those respondents who were given the opportunity to obtain an education or trade in prison, most managed to complete their education or trade as part of the rehabilitation process in prison, which has given them a chance to present some knowledge to potential employers. Some respondents were interviewed at their place of employment. The fact that most of the respondents committed property related crimes, such as housebreaking, robbery and theft, which are economically related, suggest that there is a need for them to sustain themselves.

In this study two thirds of the respondents were unemployed at the time of their arrest. A tertiary qualification improves the chances of employment significantly. The money earned from being employed is, in most cases, not sufficient to satisfy the needs of the person. Most of the respondents who were employed stated that the money they earned did not satisfy their needs. They indicated that an income of R4000 per month would satisfy their needs.

Crimes committed by respondents also included murder, possession of drugs and public violence. These crimes are influenced by drugs, bad friends and unemployment (needing money) and therefore the main prompts for committing these crimes. These crimes were mostly committed at the victims' homes, on the streets and at shopping malls. One third of the crimes were committed while the respondent was alone, as opposed to two thirds being committed with one or more accomplices. Very few of the respondents are of the opinion that crime does pay. On the issue of crime being a social trend, the respondents' opinions are evenly divided.

The mean age of arrest for the respondents in this study is 19 years old; the age of first arrest for females is significantly greater than for males. The age of arrest of repeat offenders is significantly lower than that of non-repeat offenders.

\section{Verification of Research Assumptions}

\subsection{Assumption 1: Unemployed YouthrResiding in Cato Manor Commit Crime to sustain themselves}

The study revealed that most of the respondents found themselves unemployed due to a number of factors that influenced their lives, including being raised by a single parent or grandmother; unemployed parents; the need to provide in some way or the other; desperation; social influence, like peer pressure; and the need to fit into society. At first, turning to crime with a group of friends with similar backgrounds was a necessity and then it developed into a means of easy cash and then petty crime escalated into more serious crime with greater rewards. Most respondents did not stop their criminal activities until they were arrested. This indicates that crime was a new-found profession for most respondents. The researcher has now gained an insight into the life world of respondents. This has placed the researcher into a position of engaging the community through a multi-disciplinary approach, involving various community role players, 
government departments and non-governmental organizations, to tackle the root or contributing causes of crime. This is in line with the South African Police mandate, in participating in endeavors to address the root causes of crime. The present approach by government to introduce the youth wage subsidy, to assist youth to obtain practical experience in different professions and trades, is yet one more innovative idea to alleviate unemployment amongst youth. The South African Police could sensitize the community to these contributing causes, through the various forums, and thereby implement a joint strategy to deal with it.

\subsection{Assumption 2: Youth who are Unemployed for Lengthy Periods turn to Crime}

The study found that most respondents were unemployed (70.6\%) at the time of their arrest, however lengthy periods of unemployment influenced certain types of crimes and yet, it proves that respondents did turn to crime after lengthy periods of unemployment. Respondents in age categories of above 25 years revealed more susceptibility to violent property crime, such as robbery (43.3\%), as opposed to those in the younger age category, which committed more housebreakings and thereby avoiding contact with victims. The study also revealed that respondents felt that there was no other way to sustain themselves $(67.5 \%)$ other than turning to crime. Therefore this indicates that there was or is no other social mechanism to assist respondents in seeking other methods of obtaining basic needs such as a meal, amongst other basic necessities. Structures, such as a centre for youth affairs involving social workers, nongovernmental organizations and social crime prevention officials are important in a community, to provide the necessary care and guidance to youth in these positions. These services are provided to minimize the risk of youth turning to crime. The absence of such avenues limits the options given to youth to deal holistically with the various challenges they face on a daily basis. The South African Police Service remains an organization at the end of all social dysfunction, but has mounds of information to share with the community, to prevent certain social ills. The maintenance of order remains a core function of the police and yet so much could be done to assist youth showing tendencies of criminal behaviour or signs of heading in that direction. Programs could therefore be put in place for the early identification of this behaviour.

\subsection{Assumption 3: Property Related Crime in Cato Manor is a Direct Result of Unemployment}

This study revealed that most respondents (35.9\%) did not complete high school due to various factors in the familial unit or environment, however the study also revealed that most respondents were of the opinion that education was important to them. Most respondents were under the age of twenty at the time of their first arrest and they were mostly arrested for the crime of housebreaking and theft. Respondents could not obtain gainful employment as their personal profile did not appeal to employers, as they did not have all the basic qualifications to enter the job market, due to the factors mentioned earlier, compared with other youth who were also applying for the same jobs. This led to them being unemployed for lengthy periods. The fact that they were arrested for property related crimes and mostly housebreaking, reveals to the researcher that they stole property to sell in order to get money to buy the necessities that they needed to get by in their daily lives, including providing for their families and siblings. The study therefore supports the hypothesis that property related crime is a result of unemployment. A newspaper article with the caption 'Great strides made in reducing extreme poverty' states that the global target of reducing extreme poverty to half the 1990 levels by 2015, appears to have been achieved three years ahead of schedule, according to the Millennium Development of Goals Report for 2012. The report also reveals that Africa is finally beginning to show real progress towards achieving a better life for all. South African statistics indicate that the proportion of people living below the poverty line dropped from 31\% to 23\% between 1995 and 2006 (Sunday Tribune, 2012). This indicates that the government and businesses are looking at ways to reduce the poverty gap, by providing employment opportunities to alleviate poverty.

\section{Discussion of Findings}

The study revealed that most respondents in this study came from broken homes, in that they were raised either by a grandmother or a single parent. In cases where the respondents were raised by a single parent, that parent had to work in order to provide for the family and that lead to the respondent being away from proper supervision in the home environment. There is a more compounding problem when one looks at the dysfunctions within the family of respondents and the friendships that these individuals develop with other youth of similar backgrounds. This means that respondents were left unsupervised the community, after school and thus allowing other elements to influence the individual. Other scholars argue that peer groups and activities have always been linked to delinquency, as it exists in previous literature (Obioha and Nthabi, 2011:174). The further findings from this study on delinquent behaviour indicated that most 
respondents have more than one close friend. More than one close friend is close to a gang, which relates with what the literature documents, that juveniles who join gangs are likely to engage in delinquent behaviour. The area of Cato Manor is regarded as a residential area for low to middle income earners, which inherently exposed respondents to elements of drug dealing, property and social contact crime. These crimes were being perpetrated by individuals known to respondents in this study and in some instances, the victims of these crimes were also known to the respondents. Respondents were influenced by the individuals perpetrating these crimes, as they saw this as a way out of their circumstances and to provide for their families. The category of respondents, who were mostly involved in robbery, housebreaking, sexual offences and even stock theft, were recorded high amongst the group who had once used drugs. This signifies that the greater the number of close friends and the use of drugs, the higher the chances of engaging in delinquent behaviour, especially economic related crime (Obioha and Nthabi 2011: 175). In this present study, 65\% of respondents had committed crime with one or more friends, as well as $60 \%$ of friends had been arrested previously for property related crime. Further to those dysfunctions, there is the lack of obtaining an education and staying in the educational environment, due to the lack of stability in the home. Most respondents had been arrested more than once and this is not indicative of the number of times they have perpetrated crime. However, it proves that once they had enjoyed the benefits of their deeds, they continued to sustain the lifestyle until they were arrested.

The researcher acknowledges that most respondents in this study were male individuals, as opposes to females, even though females were also exposed to the same conditions as their male counterparts. Almost all respondents were of the opinion that education was important to succeed in life, but their circumstances placed them in difficult and desperate situations at the time. The types of crimes committed by respondents is also indicative of the type of life circumstances that they were exposed to, as they had committed crime to sustain themselves at first and thereafter it escalated to property related crime and other economic crimes. Obviously, findings from the study further revealed that most respondents were unemployed at the time of their arrests, especially those in the younger age category (18- 21 years) and that is what the study intended to establish.

Other studies, similar to this one, have revealed that staggeringly high unemployment rates in the highest crime communities in the United States are beyond dispute (Sherman 1998: 28). Burger (2007:48) goes on to opine that research has also shown that police crackdowns in areas of high unemployment have given large numbers of young men criminal records for minor offences, limiting their chances of employment and increasing their likelihood of entering into further and more serious criminality. Similarly, Sherman et al (1998:59) also found that employment is undoubtedly the primary factor in the development of healthy social bonds and institutions in a community and conversely, that unemployment usually results in crime and disorder.

This study has shown that instability exists in the home of respondents, as most have grown up with a single parent, mainly the mother; some respondents did not even know who their father was. Some respondents' mothers were not the only wife of their father, which indicates that those respondents hail from polygamous family backgrounds. This clearly outlines that the social cohesion that should exist at home, though not forgetting the primary source of employment which creates this, is diminished by insufficient care by both parents in the development of youth, thus providing a conduit for a poor foundation in life, an improper education and ultimately a lack of gainful employment. Bartollas (2006:105) gives a recovering delinquent's account of how he turned to crime. Sam, an institutionalised delinquent, made this statement shortly before he left an end-of-the-line training school:

\begin{abstract}
"You know I never had a father or, at least, I didn't know him. I have a good mother, but she has had a hard life. At times, we barely have enough food to eat. The last time I was released from Fairfield, I made up my mind to stay out of trouble. My friends kept coming around with their schemes, and I told them to get out of my face. Then, my mother needed surgery, and there wasn't any money. My friends wanted to hit (rob) a liquor store, and I went along. But we got caught, and I ended up here. l've grown a lot lately. It hasn't been the institution and the silly-ass rules. It has been people like John and you. You've given me respect. I want to make something of myself now. I'm eighteen, and l've got my high school diploma. I want to make a contribution to my people. Blacks have been held down too long. But I know it won't be easy to stay out of trouble. l've got to go back to the same neighbourhoods, the same old buddies. Street life will always be there for me. I know it will be prison next time, and I don't want to spend the rest of my life in and out of places like this."
\end{abstract}

A family is recognized by sociologists and criminologists as the first and most important agent of socialization, where personality formation begins. In families characterized by separation, death of one parent or both and divorce, the child grows up in an unstable environment different from the normal type of family. In such a family, there may be loose moral control and instability, which may result in ineffective socialization of a child, thus there is a big chance of a child deviating from the norms of society. Moreover, the stress associated with the instability may lead a child to engage in 
delinquent behavior in pursuit of happiness and a sense of belonging that the child in deprived of in his or her family (Obioha and Nthabi: 2011:174).

Some respondents opted not to obtain an education as part of rehabilitation, whilst under correctional supervision and this is a worrying factor, given the notion that certain inadequacies lead to crime, but this informs the researcher that some individuals who wished to lead a straight and lawful life, has been so adversely affected by factors which some would say are beyond their control, that the only life they see now is one of crime.

\section{Conclusion}

Some scholars in summing up their research on crime and unemployment state that on the balance of weight, research supports there being a weak, but none the less significant casual relationship. However, properly targeted research on young mobs, particularly those from disadvantaged ethnic groups, which considers both the meaning and duration of unemployment, has yet to be done. This study looked at the individual who has committed a crime, being a youth from a disadvantaged ethnic group and given the environment in which he grew up and has revealed a caused relationship between relative deprivations and crime, particularly where unemployment is perceived as unjust and hopeless, by comparison with other groups.

In this study it was observed that $40.4 \%$ of respondents who reside in Chesterville have committed more property related crimes compared to other socially related crimes like murder, as opposed to those residing in other sections within the Cato Manor area. The general area of Cato Manor is regarded as a disadvantaged impoverished area, however from this study it is evident that more emphasis needs to be placed on Chesterville, as the most contributing area. This study has also revealed more than just unemployment as a factor leading to crime. It revealed more social background issues, such as growing up in a dysfunctional family where one parent or both parents are/were not involved in the upbringing of respondents; lack of education and the need for respondents to support their families by looking for other means (most often crime) to assist in putting food on the table. This implies that most youth did not obtain the standard of education required to receive gainful employment. The use or abuse of drugs compounds the issue, as these addictive drugs cause the individual to develop a hunger to commit crime, in order to support their habit individually or as part of a group sharing similar dysfunctions in the family.

\section{References}

Burger, J. (2005). Direct and Indirect Policing. Servamus, 20 (4): 74-76.

Burger, J. (2007). Strategic Perspectives on Crime and Policing in South Africa. Pretoria: Van Schaik.

Chapman, B., Weatherburn, D., Kapuscinski, C.A., Chilvers, M., \& Roussel, S. (2002) Unemployment duration, schooling and property crime. Crime and Justice Bulletin, Dec. 2002.

Coad, P. (2007) Crime and unemployment, March 26, 2007, available at: http://www.google.html.

Lab, S.P. (2010) Crime Prevention Approaches, Practises and Evaluations. New York, United States: LexisNexis.

Obioha, E. E. \& Nthabi, M. A. (2011) Social Background Patterns and Juvenile Delinquency Nexus in Lesotho: A case study of Juvenile Delinquency in Juvenile Training Centre(JTC), Maseru. Journal of Social Science, 27(3):165-177

Sherman, LW (1998) Evidence-based Policing. Ideas in American Policing. Washington: Police Foundation.

Sherman LW, Gottfredson D, Mackenzie D, Eck J, Reuter P, \& Bushway S, (1998) Preventing Crime: What Works, What Doesn't, What's Promising. Washington, D.C.: Office of Justice Programs, National Institute of Justice

Statistics South Africa (2001) Unemployment and crime. Available at: http://www.statssa.org.html.

Sunday Tribune (2012) "Great strides made in reducing extreme poverty",22 July, p.5. 